\title{
Research on the Thinking and Methods of Exhibition Prop Design from the Perspective of Semiology
}

\author{
Gong Qian \\ Department of Industry design ,Hubei Institute of Fine Arts,430205,China
}

\begin{abstract}
This paper explains the concept of exhibition prop, analyzes the characteristics of the artistic exhibition props based on the semiotic theory, studies the design methods of exhibition props from the perspective of semiology, discusses the whole process from element extraction to symbol generation and functionalization and expound various design ideas of exhibition props, looking forward to provide guidance on the design thinking and methods.
\end{abstract}

Keywords-exhibition prop; semiology; design thinking; design methods.

Exhibition prop design is the main carrier to realize the exhibition function. Exhibition prop design has discipline intersection with industrial design, but the difference is that the foil property of props decides the relation of primary and secondary with the exhibits. Exhibition prop design involves not only the engineering practice part like market research, product design and material structure processing technology, but also many basic devices in the selling space and basic exhibition carriers in museum and other spaces. Due to the wide coverage of knowledge, it needs to be developed on the premise of various knowledge foreshadows and studied based on the combination of theory and practice.

In the fiercely competitive exhibition industry, how to avoid the simple imitation and homogeneity of exhibition props is growing in intensity. How to enhance the design connotation, how to internalize the brand image and multiple functions into exhibition props, how to make the flexible design of exhibition space and realize the guidance of the spatial streamline, how to determine the center and focus of the exhibition space and present a refreshing and surprising result, how to make exhibition props coincide with the logic of the exhibition information and create an aesthetic feeling...To meet all those requirements, it's urgent to introduce the semiotic theory and methodology. In this paper, the thinking, methods and application of exhibition prop design are analyzed, constructed and guided by the scientific, mature and systematic design semiology.

\section{OVERVIEW Of SEMIOLOGY}

Semiology is divided into syntactics, semantics and pragmatics in the semiotic theory. In the exhibition prop design, syntactics focuses on the construction of the exhibition prop symbol system--- extraction of design elements and element symbolization. Semantics focuses on the relationship between the prop design symbols and their reference exhibition information and contents --- making the symbols functional and informative through association and symbolization, deconstruction and construction, meaning extension and spirit displaying. Pragmatics puts emphasis on the analysis and coding of the information conveying mechanism of exhibition props as well as the analysis of the coordination mechanism and information reconstruction in the level of information communication.

\section{OVERVIEW OF EXHIBITION PROPS}

"Prop" is interpreted as the stage instrument needed for drama, movies and other shows. In the category of exhibition design, the instruments bearing the information and exhibits are all called exhibition prop. It's the background, stage and contrast of the exhibit and theme as well as the material and technical basis of exhibition. It's performed by placing, bearing, maintaining and hanging. It can also constitute the space image to create a unique visual atmosphere. Exhibition props are the material basis of exhibition, the link connecting exhibits, space and human as well as the bridge ensuring the successful information communication. It not only bears exhibits and expresses the exhibition information, but also conveys the exhibition image and affects exhibition space cutting, space form and space.

Exhibition prop design from the perspective of semiology integrates artistry and functionality together, applies new technologies and materials ingeniously, holds the visual image of brands and internalizes the brand spirit, thus becoming the new trend of exhibition design discipline and exhibition industry development.

\section{EXHIBITION PROP DESIGN IDEAS BASED ON SEMIOLOGY}

\section{A. Association and imagination}

Association and imagination are common ideas in the exhibition prop design creation. They are the most powerful driving force for the design creation development and change. Exhibition prop design can also form new creative thinking breakthroughs by means of association and imagination. Designers think from new perspectives through grasping the design theme, exhibition content and characteristics of exhibits to open their minds and find relevant creation images and symbol systems. 


\section{B. Concretness and abstractness}

When making the exhibition prop design, designers can adopt the creation methods of concreteness and abstractness. Concreteness is the symbol association way based on the design content representation. The designed props intuitively exhibit the exhibition theme and connotation. Designers capture the intuitive modeling and colors in the exhibition theme and content and inject them into the design creativities of exhibition props to form a work structure which can let visitors have intuitive imagination, construct association and express the exhibition theme, and props themselves can also play the imperceptible spreading role through the visitors' participation experience. Abstract association and imagination is to extract and summarize the intentional themes and apply them to the prop design to form the abstract visual and sensory experience and constitute the exhibition props with wide scope of application.

\section{Deconstruction and construction}

Deconstruction and construction is a thinking method of design creation. It's especially apparent in the evolution of the schools of architectural design. Deconstruction is to rethink the familiar things, break the habitual design form and look for new evolution and creation. It's not the thorough destruction and negation of the past but making the creative thinking under the fixed modular design requirements and content, expand design contents and requirement system and look for new possibilities for rearrangement and combination among the elements and functions of the system.

In the exhibition prop design, the deconstruction process implies the possibility of reconstructing the system. Deconstructing the form and functions of exhibition props can form rich symbolic images. Reconstruction and presentation of the design content will not eliminate the deconstruction of design contents, but redisplay the concrete part of deconstruction creatively in the process of recoding and making the whole work present an integrated construction system. Deconstruction also contains the design level and creation ideas of designers. They analyze and study the past exhibition props, fully understand many links like design, material, use and feedback, find and solve problems and inject new creative thinking processes in the design deconstruction and construction, which is also an important source of ideas for the designers to determine their own design styles and thoughts.

\section{Divergence and convergence}

Divergence and centralization is a creative thinking method that designers look for possible design results from multiple angles. Divergent thinking requires designers to be quick-witted for creative thinking according to the design contents from multiple angles and create several ideas and methods in a short period of time. During the thinking process, they act according to circumstances, draw an analogy, break through the fixed mental set of the design object, change the thinking perspectives and thus find new ideas and creativities. Convergence is to look for key ideas and creativities created by divergence, classify and push them and finally realize the functionalization.

The design idea of divergence and convergence requires the exhibition prop designers to have the rich knowledge structure and broad knowledge platform. Knowledge accumulation is the basis of divergence and convergence. In the exhibition prop design, designers need to make the deep market investigation, get familiar with the structure, material and processing technology of exhibition props, fully dig the properties and requirements of exhibits and combine the enterprise image or design concept to design the declarative and expressive exhibition props according to the exhibition information and the characteristic theme of the space.

\section{Exhibition Prop Design Methods BAsEd ON SEMIOLOGY}

\section{A. Extraction of design elements}

Design elements can be extracted from several angles like form, texture, color, audience and implication based on full understanding of the design theme. The thorough understanding of the design contents is the premise of element extraction and symbolization. At the same time, designers should also make the horizontal and vertical analysis on the knowledge related to the exhibition theme and extract the elements reasonably and vividly, which is the initial step of the exhibition prop design method. For example, designers can look for the design elements from the abstract concepts, instantaneous perceptual knowledge or pure geometry and think from the nature, the appearance or characteristics of animals and plants, cultural symbols as well as form and pattern of buildings or crafts.

\section{B. Element symbolization}

Symbolizing the extracted elements with the principles of semeiology and based on the actual exhibition prop design projects and requirements, which is a key link in the realization of the artistic characteristics of exhibition prop design. The symbols of elements should be based on the theme and information, conform to the aesthetic principle and adapt to the continuous development and change of the times based on creatively inheriting the traditional element symbols.

Exhibition prop design needs to use new forms skillfully based on the original contents like exhibition booth, cabinet, shelf and board to create a suitable design symbol, or change some conventional combination relationship among symbols conventionally to create the novel and charming exhibition prop works.

Gao Yingui proposes that there are three methods for element symbolization: extraction, transplantation and transformation. Extraction is to extract the special symbols and arrangements from the exhibition content and meet the visual and aesthetic demands of modern exhibition space with new techniques. It's not just the concrete imitation visually, but looks for the blending points in aesthetics. Transplantation is to keep the extracted element symbols selectively, maybe some fragments or symbol arrangement 
patterns and transplant new design to the original prop forms to renew them. Transformation is to deform or split some common symbols or change the code compiling order in the case that some accustomed props cannot attract the visitors' attention, in order to strengthen the exhibition information

\section{Symbol functionalization}

The development process of exhibition props is also the continuous improvement process of their functions. Their function develop from simple exhibition and exhibit storage to planning the space and guiding the visitors, from displaying exhibits to helping creating the space atmosphere and deepening the space theme, from the simple exhibition function to the main body of the space. In summary, the compound functions of exhibition props, such as bearing exhibition, planning the space, guiding the visitors, creating the space atmosphere, strengthening the brand image and presenting artistically, promote the possibility of the exhibition prop design innovation and extend new space for the research of the exhibition prop design from the perspective of semiology.

\section{Symbol deepening and perfection}

Deepening the symbol elements based on the previous ideas make the exhibition prop design own the unique internal character, show the characteristics of the theme and create the space atmosphere, thus becoming an important part in the exhibition activities. In the actual design process, in the existing exhibition space, exhibition props are no longer the traditional exhibition booth or cabinet, but can be changed according to the space atmosphere. Designers combine props with the whole exhibition space by changing their colors and materials and create the unique exhibition space through grasping the color and shadow of the space and applying the props of the same series, so as to highlight the exhibition theme more effectively.

\section{CONCLUSION}

This paper makes the semiotic theory probe into the research of the setting, implementation methods and ways of multiple objectives like exhibition prop thinking training, design process and application feedback, and apply the semiotic theory and methodology into the systematic thinking method of exhibition prop design. The research is based on the design method, thinking, technical application and communication mechanism of functional, expressive and declarative exhibition props with the particular theme, background, requirement and information. It has important theoretical significance and application value in not only promoting the design quality of the exhibition industry and developing and applying the production, teaching and research of exhibition props, but also tamping the basic research of the exhibition design discipline and improving the exhibition design talents.

\section{REFERENCE}

[1] Gong Qian .The system of exhibition props research.Southwest China Normal University Press,2015 